Check for updates

Cite this: Chem. Commun., 2018, 54,184

Received 17th October 2017, Accepted 24th November 2017

DOI: $10.1039 / c 7 c c 08035 b$

rsc.li/chemcomm

\section{Fluorescence detection and removal of copper from water using a biobased and biodegradable 2D soft material $\dagger$}

\author{
Meng Li, (D) ${ }^{a}$ Zhijiang Liu, ${ }^{a}$ Shuwen Wang, ${ }^{b}$ David G. Calatayud, ${ }^{c}$ Wei-Hong Zhu, (D) \\ Tony D. James, (D) ${ }^{* d}$ Lidong Wang, (D) *a Boyang Mao*ef and Hui-Ning Xiao*a
}

\begin{abstract}
We have developed a green and robust fluorogenic $\left(\lambda_{\mathrm{ex}}=410 \mathrm{~nm}\right.$, $\lambda_{\mathrm{em}}=\mathbf{5 1 0} \mathrm{nm}$ ) cellulose membrane using graphene oxide (GO) as a construct for simultaneous copper ion recognition and filtration at environmentally relevant levels. The detection limit and removal limit of $\mathrm{Cu}^{2+}$ are $7.3 \times 10^{-7} \mathrm{M}$ and $1000 \mathrm{ppm}$, respectively. The simplicity and scalability achieved for the detection and removal of metal ions in waste water is particularly noteworthy given the significant problems associated with metal ion pollution of drinking water.
\end{abstract}

Heavy metal pollution by the manufacturing industry is a worldwide problem. ${ }^{1,2}$ Such pollutants can contaminate rivers or/and lakes and be a major problem for drinking water. ${ }^{3,4}$ Among all the heavy metals, copper is one of the most common and hazardous elements, and excessive intake of copper ions $\left(\mathrm{Cu}^{2+}\right)$ can contribute to serious diseases such as Alzheimer's disease and haematological manifestations, thus influencing human longevity. ${ }^{5,6}$ Consequently, it is necessary to develop methods for the rapid detection and removal of copper ions. ${ }^{7,8}$ Among the various analysis methods, fluorescence sensors are extensively investigated due to their high sensitivity and the need for only simple instrumentation. ${ }^{9-13}$ In particular, naphthalimide-based fluorescent sensors have been reported as metal ion sensors owing to their excellent photophysical properties, such as high extinction coefficient, excellent quantum yield, outstanding photostability, and relatively long emission wavelength. ${ }^{14-16}$

\footnotetext{
${ }^{a}$ Department of Environmental Science and Technology, North China Electric Power University, Baoding 071003, P. R. China.E-mail: wld@ncepu.edu.cn

${ }^{b}$ Shanghai Key Laboratory of Functional Materials Chemistry, Key Laboratory for Advanced Materials and Institute of Fine Chemicals, East China University of Science \& Technology, 130 Meilong Road, Shanghai 200237, P. R. China

${ }^{c}$ Department of Electroceramics, Instituto de Ceramica y Vidrio CSIC, Kelsen 5, Campus de Cantoblanco, 28049, Madrid, Spain

${ }^{d}$ Department of Chemistry, University of Bath, Bath, BA2 7AY, UK.

E-mail: t.d.james@bath.ac.uk

${ }^{e}$ National Graphene Institute, The University of Manchester, Manchester, UK.

E-mail:boyang.mao@mancester.ac.uk

${ }^{f}$ School of Physics and Astronomy, The University of Manchester, Manchester, UK

$\dagger$ Electronic supplementary information (ESI) available. See DOI: 10.1039/ c7cc08035b
}

Also, methyl piperazine is an ideal receptor for copper ions due to coordination with the nitrogen. ${ }^{17}$ Therefore, a naphthalimide-based sensor containing methyl piperazine as the receptor is particularly suited for copper ion sensing.

Amongst all the techniques employed for the removal of copper, membrane filtration is one of the most efficient and simple methods. ${ }^{18,19}$ Over the past few years, cellulose based membranes have emerged as promising alternatives to conventional heavy metal adsorbents. $^{20-23}$ Compared to polymer films, cellulose membranes are bio-based and biodegradable materials, ${ }^{24,25}$ making them suitable for environmental applications. Cellulose-based fluorescent films have been previously reported as sensors for metal ions. ${ }^{26-28}$ However, there are only a few examples in the literature where dualfunctional materials have been reported for the simultaneous detection and removal of $\mathrm{Cu}^{2+} \cdot{ }^{29,30}$ Such materials have huge potential in sensing and purification technologies, which could contribute to the development of sensing devices.

In order to fabricate fluorescent cellulose-based films, chemical modification and physical diffusion have been extensively used. ${ }^{31,32}$ However, the low grafting ratio presents a significant challenge. Herein, we developed a new method to introduce a naphthalimide-based fluorescent molecule onto the surface of the cellulose membrane using graphene oxide (GO) as an intermediate. ${ }^{33}$ GO possesses a two-dimensional network of $\mathrm{sp}^{2}$ and $\mathrm{sp}^{3}$ carbons and displays useful functionality and processability due to the oxygen-containing functional groups contained in its basal planes and edges (Fig. S1, ESI $\dagger$ ). ${ }^{34-36}$

GO can be coated directly onto a cellulose surface via H-bonding (Scheme 1). Thus, immersing a cellulose film with a GO suspension is an efficient approach to modify the cellulose membrane, which not only enhances the binding ability between the cellulose film and fluorescent molecules through a stacking process, but also influences the surface wettability. The surface hydrophobic performance was characterised using a static contact angle and is shown in Fig. S2 (ESI $\dagger$ ). The contact angle between a water drop and the film decreased from $81.0 \pm 0.3^{\circ}$ to $54.2 \pm 0.2^{\circ}$ after GO modification of the cellulose membrane, demonstrating that GO has been successfully 


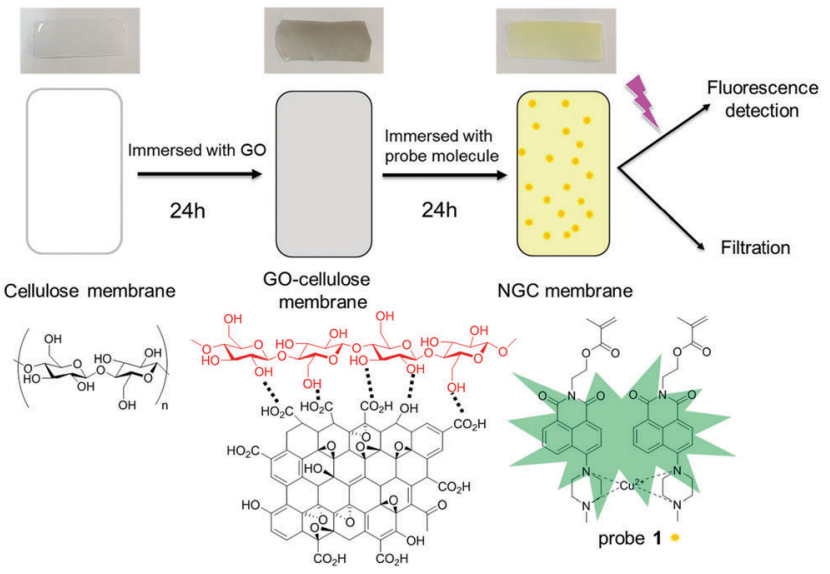

Scheme 1 Schematic representation of the cellulose membrane, GO-cellulose membrane and modified NGC membrane.

grafted onto the surface of the cellulose membrane and resulting in a more hydrophilic membrane. The hydrophilic nature of the GO-cellulose membrane should enhance its metal extraction ability in an aqueous environment. The Brunauer-EmmettTeller measurement (Fig. S3, ESI $\dagger$ ) indicates a significantly increased surface area from $4.813 \mathrm{~m}^{2} \mathrm{~g}^{-1}$ to $12.660 \mathrm{~m}^{2} \mathrm{~g}^{-1}$ after coating with GO. The increased surface area confirms the formation of the $\mathrm{GO}$-cellulose membrane, and also provides around $300 \%$ more reaction area and more binding sites.

The interaction between the naphthalimide-based fluorescent molecule and GO was investigated using electrostatic simulations. Different $\pi-\pi$ stackings between the fluorescent molecules and GO were proposed using the Hunter and Sanders (HS) model and calculations of the electrostatic surface potentials (Fig. 1, detailed discussions can be found in the ESI, $\dagger$ Fig. S4 and S5). From the results, it can be seen that naphthalimide-based fluorescent molecules can be readily attached to the GO surface by $\pi-\pi$ stacking.

The first step in the fabrication of the naphthalimide based GO-cellulose (NGC) sensor membrane requires cellulose with appropriate properties. Therefore, in order to enhance the adsorption capacity, pre-treated cellulose and TEMPO (2,2,6,6-tetramethylpiperidine-1-oxyl radical) oxidised cellulose $(1: 1, \mathrm{wt} \%)$ were dissolved in a $\mathrm{NaOH} / \mathrm{urea}$ solution at low temperature. The degree of TEMPO oxidisation of the cellulose was evaluated using a conductivity titration method (Fig. S6, ESI $\dagger$ ). The $\mathrm{COOH}$ content was calculated to be $1.05 \mathrm{mmol} \mathrm{g}^{-1}$. The mixture was coated onto a glass plate and precipitated using ethanol. The thickness of the resulting membrane was found to be around $20 \mu \mathrm{m}$. The precipitated membrane was then immersed in a GO suspension for $24 \mathrm{~h}$ and subsequently in a solution of probe 1 for $24 \mathrm{~h}$, resulting in NGC membrane fabrication. The direct surface morphology of the cellulose based membranes was observed using scanning electron microscopy (SEM) measurements (Fig. S7, ESI $\dagger$ ). After GO coating, the surface of the membrane becomes smooth and less bumpy. The attachment of the naphthalimide-based sensor molecules can be observed in the SEM images. Probe $\mathbf{1}$ was prepared following

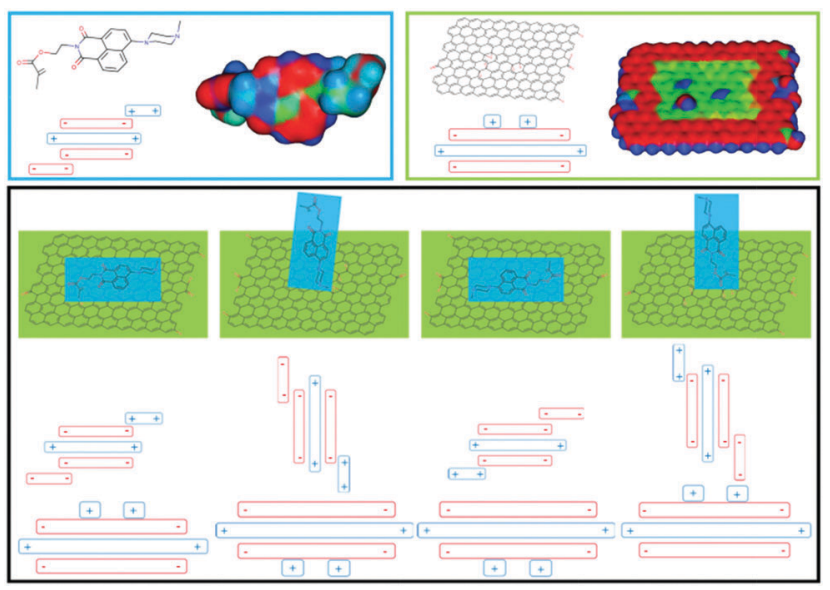

Fig. 1 Top: Optimised structures of probe 1 and GO (red denotes areas of relatively high electron density and blue denotes electron deficient areas). Bottom: Proposed stacking arrangements.

the previously published method ${ }^{37}$ and was fully characterized by ${ }^{1} \mathrm{H}$ NMR and ${ }^{13} \mathrm{C}$ NMR (Fig. S8, ESI $\dagger$ ).

To investigate the $\mathrm{Cu}^{2+}$ fluorescence sensing behaviour, the fluorescence spectra of the NGC membrane in the absence and presence of $\mathrm{Cu}^{2+}$ were investigated (Fig. S9a, ESI $\dagger$ ). The NGC membrane alone exhibits almost no emission when excited at $410 \mathrm{~nm}$ and with no variation after extended periods of time, indicating that the NGC membrane is very stable. However, in the presence of $\mathrm{Cu}^{2+}$, the fluorescence of the NGC membrane at $510 \mathrm{~nm}$ was significantly enhanced. While the cellulose membrane without a GO coating (NC membrane) was also evaluated using fluorescence measurements (Fig. S9b, ESI $\dagger$ ). In comparison, as shown in Fig. 2, the intensity of the NGC membrane is about 3 times higher than that of the $\mathrm{NC}$ membrane, indicating that more fluorescent molecules have been attached to the cellulose membrane mediated by GO. The detection limit by the NGC membrane could reach $7.3 \times 10^{-7} \mathrm{M}$ (Fig. S9c, ESI $\dagger$ ).

In order to gain insight into the fluorescence mechanism, the fluorescence spectra of probe 1 was also examined (Fig. S10, ESI†).

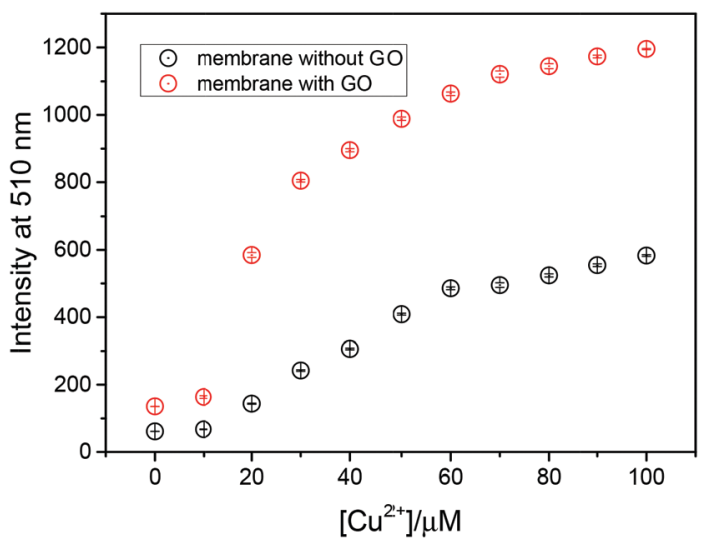

Fig. 2 Fluorescence intensity at $510 \mathrm{~nm}\left(\lambda_{\mathrm{ex}}=410 \mathrm{~nm}\right)$ of probe 1 attached to the cellulose membrane with and without a GO coating. 
The probe 1 showed weak fluorescence due to the strong photoinduced electron transfer (PET) effect with piperazine moieties as electron donors. The PET effect can be efficiently blocked by the coordination with $\mathrm{Cu}^{2+}$, therefore the strong fluorescence of the 1,8-naphthalimide was restored. ${ }^{38}$

To assess the filtration capacity of the NGC membrane, the effect of different initial concentrations of $\mathrm{Cu}^{2+}$ on the filtration capacity was evaluated (Fig. 3a). The $\mathrm{Cu}^{2+}$ uptake capacity of the adsorbents is in the range of $99-56 \%$ with increasing $\mathrm{Cu}^{2+}$ concentration from 10 to $200 \mathrm{ppm}$. After increasing the initial $\mathrm{Cu}^{2+}$ concentration, the metal uptake decreased to $10 \%$ at $1000 \mathrm{ppm} \mathrm{Cu}^{2+}$. The data suggest that the NGC membrane displays excellent retention of $\mathrm{Cu}^{2+}$ from low concentration wastewater, and reasonable retention behaviour for high concentrations. In addition, the membrane cross-section was imaged using cryogenic scanning electron microscopy (cryo-SEM) coupled with energy dispersive X-ray spectroscopy (EDS) in order to determine the location of the metal ion retention in the membrane. From the SEM images, a porous distribution of cellulose layers is observed for the NGC membrane ( $c a .19 \mu \mathrm{m}$ thick, Fig. 4a and b). The EDS mapping image (Fig. 4c and d) indicates that the $\mathrm{Cu}^{2+}$ ions are uniformly located within the cellulose layer after filtration. The $\mathrm{Cu}^{2+}$ is evenly distributed in the membrane, confirming that the removal of $\mathrm{Cu}^{2+}$ is via absorption. The removal mechanism also indicates that a higher removal rate of $\mathrm{Cu}^{2+}$ can
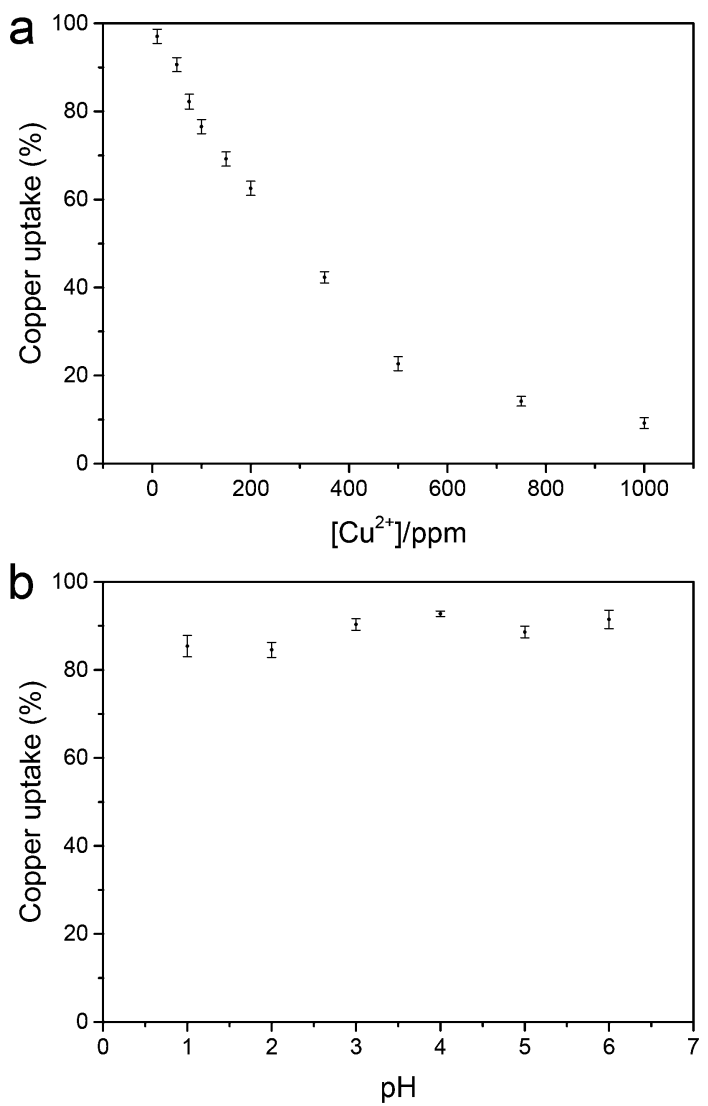

Fig. 3 (a) Metal uptake as a function of $\mathrm{Cu}($ (I) ion concentration and (b) metal uptake of the NGC membrane as a function of $\mathrm{pH}\left(\left[\mathrm{Cu}^{2+}\right]=50 \mathrm{mg} \mathrm{L}^{-1}\right)$.

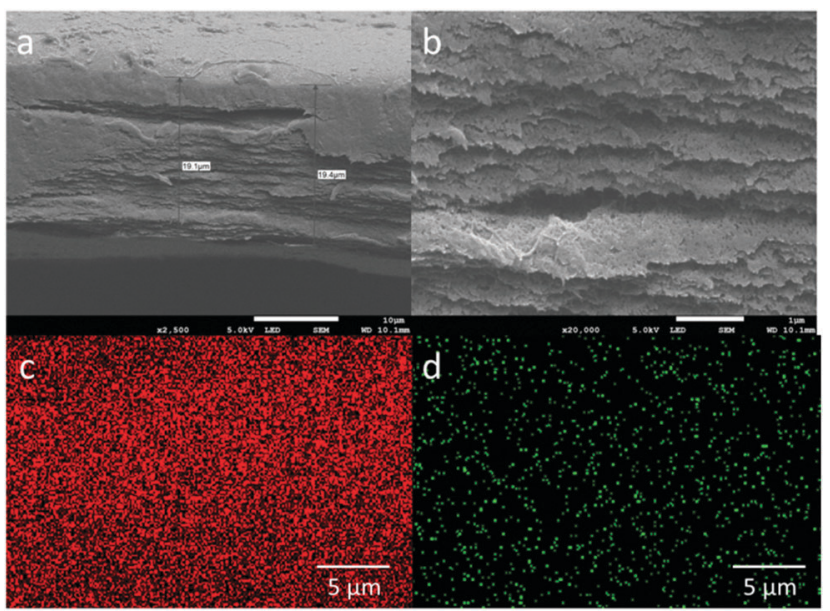

Fig. 4 Cross-sectional SEM images of (a) NGC membrane; (b) in magnified mode; EDS mapped areas of the NGC film after $\mathrm{Cu}\left({ }^{\prime \prime}\right)$ filtration containing (c) carbon and (d) copper.

be achieved by simply increasing the thickness and area of the NGC membrane. Furthermore, the NGC membrane performance related to retention of heavy metals is comparable to those of commonly used membranes. The effect of $\mathrm{pH}$ on the metal ion retention ability was also investigated. Significantly, the NGC membrane does not require any $\mathrm{pH}$ adjustment, Fig. $3 \mathrm{~b} . \dagger$

The recyclability of the NGC membrane is very important in environmental protection (Fig. S11, ESI $\dagger$ ). After four cycles, the recyclable adsorption behavior of the NGC membrane toward $\mathrm{Cu}^{2+}$ was similar to that after one cycle and the metal uptake was slightly decreased. The removal efficiency of the NGC membrane toward $\mathrm{Cu}^{2+}$ after one and four cycles was $91.86 \%$ and $61.26 \%$, respectively. The excellent reusability indicates that the NGC membrane could be a potential absorbent in practical applications.

Moreover, as well as demonstrating the ability to remove $\mathrm{Cu}^{2+}$, we demonstrated that the GO-cellulose membrane can be similarly extended to remove other toxic heavy metals, making the GO-cellulose membrane an ideal platform to attach other fluorescent probe molecules. The removal of other toxic heavy metals was measured using contaminant levels (MCL) ranging from a few ppm to hundreds of ppm. To demonstrate the removal of heavy metals using our GO-cellulose membrane (thickness $20 \mu \mathrm{m}$ ), we used salts of the following contaminant metals: lead $(\mathrm{Pb})$, mercury $(\mathrm{Hg})$, and chromium $(\mathrm{Cr})$. Solutions were filtered using the GO-cellulose membrane at high (200 ppm) and low (up to $10 \mathrm{ppm}$ ) contaminant concentrations. The feed solutions and filtrates were analysed using atomic absorption spectrophotometry and atomic fluorescence spectrometry; see Table 1. Superior removal of heavy metals from water was observed, with metal retention approaching $92 \%$ for low concentrations, indicating that the GO-cellulose membrane displays an excellent retention for many types of heavy metal ions in addition to $\mathrm{Cu}(\mathrm{II})$. This clearly demonstrates that we could fabricate membranes for the detection and removal of different metal ions if we used different fluorescence probes.

In conclusion, we have developed a fluorescent biodegradable cellulose membrane by dip coating with GO and a 
Table 1 Removal efficiencies of $\mathrm{Cr}^{6+}, \mathrm{Hg}^{2+}$, and $\mathrm{Pb}^{2+}$ by the NGC membrane

\begin{tabular}{llllll}
\hline & \multicolumn{2}{l}{ High concentration } & & \multicolumn{2}{l}{ Low concentration } \\
\cline { 2 - 3 } Filtered salt & $\mathrm{M}^{n+}(\mathrm{ppm})$ & $\begin{array}{l}\text { Metal uptake } \\
(\%)\end{array}$ & & $\mathrm{M}^{n+}(\mathrm{ppm})$ & $\begin{array}{l}\text { Metal uptake } \\
(\%)\end{array}$ \\
\hline $\mathrm{Cr}^{6+}$ & 200 & 54 & 10 & 91 \\
$\mathrm{Hg}^{2+}$ & 200 & 62 & 10 & 92 \\
$\mathrm{~Pb}^{2+}$ & 200 & 55 & 10 & 90 \\
\hline
\end{tabular}

fluorescence probe. The composite NGC film exhibits rapid response towards $\mathrm{Cu}^{2+}$ and excellent removal capability of copper ions. This work provides a convenient and costeffective fluorophore-doping approach for the rapid fabrication of fluorescent cellulose materials for both sensing and metal ion removal. The detection limit and removal limit of $\mathrm{Cu}^{2+}$ are $7.3 \times 10^{-7} \mathrm{M}$ and $1000 \mathrm{ppm}$, respectively. Since there are a plethora of fluorophores and receptors available it will be possible to fabricate fluorescence sensors with any desired sensing and extraction ability, resulting in an approach suitable for wide ranging metal ion sensing and removal applications.

The present work was supported by the National Key Research and Development Program of China (Grant \#: 2017YFC0210201 and 2016YFC0204102) and the National Natural Science Foundation of China (Grant \#: 21607044, 51378204, and 51379077). This work was also supported by the Natural Science Foundation of Hebei Province (Grant \#: B2017502069 and E2016502096) and the Fundamental Research Funds for the Central Universities (Grant \#: 2016MS108). T. D. J. wishes to thank the Royal Society for a Wolfson Research Merit Award. All data supporting this study are provided as supplementary information accompanying this paper (ESI $\dagger)$.

\section{Conflicts of interest}

There are no conflicts to declare.

\section{Notes and references}

1 R. Reza and G. Singh, Int. J. Environ. Sci. Technol., 2010, 7, 785-792. 2 Q. Ma, Y. Yu, M. Sindoro, A. G. Fane, R. Wang and H. Zhang, Adv. Mater., 2017, 29, 1605361.

3 M. Varol, J. Hazard. Mater., 2011, 195, 355-364.

4 M. Chabukdhara and A. K. Nema, Chemosphere, 2012, 87, 945-953.

5 R. Dringen, I. F. Scheiber and J. F. Mercer, Front. Aging Neurosci., 2013, 5 .

6 M. Schrag, C. Mueller, U. Oyoyo, M. A. Smith and W. M. Kirsch, Prog. Neurobiol., 2011, 94, 296-306.

7 M. Li, H. Ge, R. L. Arrowsmith, V. Mirabello, S. W. Botchway, W. Zhu, S. I. Pascu and T. D. James, Chem. Commun., 2014, 50, 11806-11809.
8 M. R. Awual, M. Ismael, T. Yaita, S. A. El-Safty, H. Shiwaku, Y. Okamoto and S. Suzuki, Chem. Eng. J., 2013, 222, 67-76.

9 Z. Guo, S. Park, J. Yoon and I. Shin, Chem. Soc. Rev., 2014, 43, 16-29. 10 K. Gu, Y. Xu, H. Li, Z. Guo, S. Zhu, S. Zhu, P. Shi, T. D. James, H. Tian and W.-H. Zhu, J. Am. Chem. Soc., 2016, 138, 5334-5340.

11 X. Qian, Y. Xiao, Y. Xu, X. Guo, J. Qian and W. Zhu, Chem. Commun., 2010, 46, 6418-6436.

12 G. He, N. Yan, J. Yang, H. Wang, L. Ding, S. Yin and Y. Fang, Macromolecules, 2011, 44, 4759-4766.

13 M. Li, Z. Liu, H.-C. Wang, A. C. Sedgwick, J. E. Gardiner, S. D. Bull, H.-N. Xiao and T. D. James, Dyes Pigm., 2018, 149, 669-675.

14 P. Wang, J. Liu, X. Lv, Y. Liu, Y. Zhao and W. Guo, Org. Lett., 2012, 14, 520-523.

15 W. Wang, Q. Wen, Y. Zhang, X. Fei, Y. Li, Q. Yang and X. Xu, Dalton Trans., 2013, 42, 1827-1833.

16 M. H. Lee, J. S. Kim and J. L. Sessler, Chem. Soc. Rev., 2015, 44, 4185-4191.

17 J. Qian, X. Qian, Y. Xu and S. Zhang, Chem. Commun., 2008, 4141-4143.

18 E. Cohen, H. Weissman, E. Shimoni, I. Kaplan-Ashiri, K. Werle, W. Wohlleben and B. Rybtchinski, Angew. Chem., Int. Ed., 2017, 56, 2203-2207.

19 M. Soylak, Y. E. Unsal, N. Kizil and A. Aydin, Food Chem. Toxicol., 2010, 48, 517-521.

20 R. Yang, K. B. Aubrecht, H. Ma, R. Wang, R. B. Grubbs, B. S. Hsiao and B. Chu, Polymer, 2014, 55, 1167-1176.

21 Q. Niu, K. Gao and W. Wu, Carbohydr. Polym., 2014, 110, 47-52.

22 M. Li, Z. Liu, L. Wang, T. D. James, H.-N. Xiao and W.-H. Zhu, Mater. Chem. Front., 2017, 1, 2317-2323.

23 B. Duan, C. Chang, B. Ding, J. Cai, M. Xu, S. Feng, J. Ren, X. Shi, Y. Du and L. Zhang, J. Mater. Chem. A, 2013, 1, 1867-1874.

24 D. G. Olson, S. A. Tripathi, R. J. Giannone, J. Lo, N. C. Caiazza, D. A. Hogsett, R. L. Hettich, A. M. Guss, G. Dubrovsky and L. R. Lynd, Proc. Natl. Acad. Sci. U. S. A., 2010, 107, 17727-17732.

25 S.-J. Yang, I. Kataeva, S. D. Hamilton-Brehm, N. L. Engle, T. J. Tschaplinski, C. Doeppke, M. Davis, J. Westpheling and M. W. Adams, Appl. Environ. Microbiol., 2009, 75, 4762-4769.

26 X. Liu, C. Zong and L. Lu, Analyst, 2012, 137, 2406-2414.

27 P. Srivastava, S. S. Razi, R. Ali, R. C. Gupta, S. S. Yadav, G. Narayan and A. Misra, Anal. Chem., 2014, 86, 8693-8699.

28 M. Li, X. Li, H. N. Xiao and T. James, ChemistryOpen, 2017, 6, 685-696.

29 M. R. Awual, I. M. Rahman, T. Yaita, M. A. Khaleque and M. Ferdows, Chem. Eng. J., 2014, 236, 100-109.

30 M. R. Awual, Chem. Eng. J., 2015, 266, 368-375.

31 F. Xiong, Y. Han, G. Li, T. Qin, S. Wang and F. Chu, Ind. Crops Prod., 2016, 83, 663-669.

32 S. Raj and D. R. Shankaran, Sens. Actuators, B, 2016, 226, 318-325.

33 J. Ge, L.-A. Shi, Y.-C. Wang, H.-Y. Zhao, H.-B. Yao, Y.-B. Zhu, Y. Zhang, H.-W. Zhu, H.-A. Wu and S.-H. Yu, Nat. Nanotechnol., 2017, 12, 434-440.

34 S. R. Kwon, J. Harris, T. Zhou, D. Loufakis, J. G. Boyd and J. L. Lutkenhaus, ACS Nano, 2017, 11, 6682-6690.

35 L. Huang, Y. Li, Q. Zhou, W. Yuan and G. Shi, Adv. Mater., 2015, 27, 3797-3802.

36 B. Mao, D. G. Calatayud, V. Mirabello, B. J. Hodges, J. A. R. Martins, S. W. Botchway, J. M. Mitchels and S. I. Pascu, Adv. Funct. Mater., 2016, 26, 687-697.

37 L. Shen, W. Zhu, X. Meng, Z. Guo and H. Tian, Sci. China, Ser. B: Chem., 2009, 52, 821-826.

38 J. Zhang, W. Tan, X. Meng and H. Tian, J. Mater. Chem., 2009, 19, 5726-5729. 